\title{
Individual and contextual characteristics as determinants of sagittal standing posture: a population-based study of adults
}

\author{
Fábio Araújo, MSc ${ }^{\mathrm{a}, \mathrm{b}, *}$, Raquel Lucas, $\mathrm{PhD}^{\mathrm{a}, \mathrm{b}}$, Nuno Alegrete, $\mathrm{MD}^{\mathrm{c}, \mathrm{d}}$, \\ Ana Azevedo, MD, $\mathrm{PhD}^{\mathrm{a}, \mathrm{b}, \mathrm{c}}$, Henrique Barros, MD, $\mathrm{PhD}^{\mathrm{a}, \mathrm{b}}$ \\ ${ }^{\mathrm{a}}$ Institute of Public Health - University of Porto (ISPUP), Rua das Taipas, 135-139, 4050-600 Porto, Portugal \\ ${ }^{\mathrm{b}}$ Department of Clinical Epidemiology, Predictive Medicine and Public Health, University of Porto Medical School, Al. Prof. Hernâni Monteiro, $4200-319$ \\ Porto, Portugal \\ ${ }^{\mathrm{c}}$ Centro Hospitalar São João, Al. Prof. Hernâni Monteiro, 4200-319 Porto, Portugal \\ ${ }^{\mathrm{d}}$ Department of Surgery, University of Porto Medical School, Al. Prof. Hernâni Monteiro, 4200-319 Porto, Portugal \\ Received 6 June 2013; revised 29 October 2013; accepted 17 January 2014
}

Abstract

BACKGROUND CONTEXT: Sagittal standing posture is associated with musculoskeletal symptoms and quality of life. However, the frequency and determinants of suboptimal sagittal alignment outside the clinical context remain to be clarified.

PURPOSE: To estimate the association of sociodemographic, anthropometric, and behavioral characteristics with sagittal standing posture among adults from the general population.

STUDY DESIGN: Cross-sectional evaluation of a population-based sample.

PATIENT SAMPLE: As part of the EPIPorto study, 489 adults were assessed during 2005 to 2008 .

OUTCOME MEASURES: Individual spinopelvic parameters were measured. Additionally, participants were classified into one of four types of sagittal postural patterns (Roussouly classification: Types 1, 2, and 4 corresponding to nonneutral postures and Type 3 to a neutral posture).

METHODS: Spinopelvic parameters were recorded from 36-inch sagittal radiographs obtained in free-standing posture. Age, sex, education, occupation, body mass index (BMI), waist circumference, total physical activity, leisure time physical activity, time spent in sitting position, smoking status, and tobacco cumulative exposure were collected. Individual parameters and patterns of sagittal posture were compared across categories of participants' characteristics.

RESULTS: Older age, lower educational level, blue collar occupation, and overall and central obesity were associated with increased sagittal vertical axis and pelvic tilt/pelvic incidence ratio. Taking the neutral postural pattern (Type 3) as reference for the outcome in a multinomial regression model, independently of age, sex, education, total physical activity, and smoking status, overweight adults had higher odds of Type 2 (odds ratio $[\mathrm{OR}]=1.92 ; 95 \%$ confidence interval $[\mathrm{CI}]: 1.13-3.27)$ and Type $4(\mathrm{OR}=2.13 ; 95 \% \mathrm{CI}: 1.16-3.91)$ postural patterns in comparison with normal weight subjects. Overall and central obesity were positively related with Type 1 postural pattern $(\mathrm{OR}=6.10,95 \% \mathrm{CI}: 1.52-24.57$ and $\mathrm{OR}=3.54,95 \% \mathrm{CI}: 1.13-11.11$, respectively $)$. There was also a weak direct association between female sex and Type 1 postural pattern. Regarding behavioral factors, subjects with total physical activity above the first third exhibited all nonneutral postural patterns less frequently, and current smokers were more likely to present a Type 4 postural pattern.

CONCLUSIONS: Higher BMI and central obesity were important potential determinants of nonneutral posture among adults from the general population. Future research should investigate the

FDA device/drug status: Not applicable.

Author disclosures: $\boldsymbol{F A}$ : Grant: National Foundation for Science and Technology (F, Paid directly to institution). $\boldsymbol{R} \boldsymbol{L}$ : Grant: Fundação para a Ciência e a Tecnologia (F, Paid directly to institution). NA: Fundação para a Ciência e a Tecnologia (F, Paid directly to institution). $\boldsymbol{A} \boldsymbol{A}$ : Fundacão para a Ciência e a Tecnologia (F, Paid directly to institution). $\boldsymbol{H B}$ : Fundacão para a Ciência e a Tecnologia (F, Paid directly to institution).
The disclosure key can be found on the Table of Contents and at www. TheSpineJournalOnline.com.

* Corresponding author. Instituto de Saúde Pública da Universidade do Porto, Rua das Taipas, 135-139, 4050-600 Porto, Portugal. Tel.: +351 22206 1820; fax: +35122206 1821 .

E-mail address: fabio.araujo @ispup.up.pt (F. Araújo) 
potential effectiveness of overweight prevention and management in avoiding sagittal misalignment conditions. (c) 2014 Elsevier Inc. All rights reserved.

Keywords: $\quad$ Posture; Spine; Pelvis; Radiography; Obesity; Population survey

\section{Introduction}

Sagittal standing spinopelvic alignment is a known determinant of musculoskeletal symptoms and quality of life in samples of patients with diverse spinal conditions [1-4]. Among the complex set of parameters that comprise standing posture, sagittal balance and pelvic tilt were identified as those most strongly associated with pain and physical disability $[2,3]$.

Suboptimal sagittal alignment and its attributable disability are among the most frequent reasons for adults to seek health care. In 2010, musculoskeletal spinal conditions were accountable for the loss of 116,704 disability-adjusted life years worldwide, and this indicator almost duplicated in a 10-year time frame [5]. Low back pain alone-whose patients frequently exhibit smaller lumbar lordosis and a more vertical sacrum in clinical practice [6-8]-globally accounts for the leading number of years in which individuals live with disability [5].

Conservative and surgical treatments attempting to change the prognosis of sagittal misalignment spinal conditions are available [9-12], but these approaches are commonly saved for relatively advanced stages of the disease course. Additionally, knowledge on primary prevention strategies to avoid suboptimal sagittal alignment is clearly lacking. For such evidence to be produced, research on the causes of sagittal misalignment is warranted.

The development of a suboptimal sagittal posture is a complex occurrence, reflecting exposure to diverse interrelated factors, both at the individual and contextual levels. In previous studies of adult samples selected based on the absence of clinically relevant orthopedic conditions, sagittal spinopelvic alignment was found to be associated with age [13-16], sex $[13,17,18]$, and body mass index (BMI) [19]. However, even this small group of potential determinants has not been consensual and the possible link between contextual variables and upstream sagittal standing posture phenotypes has been rarely assessed.

Furthermore, previous evidence on standing alignment has originated from highly selected samples of patients or healthy subjects, probably excluding an important fraction of population variability and limiting the generalizability of findings regarding the general adult population.

Recently, it was suggested that the study of extreme sagittal alignment etiology should be based on overall postural patterns rather than on single alignment parameters $[18,20,21]$. Nevertheless, postural patterns have seldom been researched, namely regarding their population frequency and potential determinants.

Identifying individual and contextual determinants of nonneutral sagittal standing posture among adults from the general population may allow for the recognition of groups that will be more likely to develop sagittal posture-related diseases and for the development of primary prevention strategies focusing on modifiable determinants.

Using data from a population-based sample of adults, our aim was to estimate the association of sociodemographic, anthropometric, and behavioral characteristics with sagittal posture, considering both individual alignment parameters and standing postural patterns.

\section{Participants and methods}

Participants were evaluated as part of the EPIPorto cohort study that comprises a sample of Portuguese adults, living in the city of Porto. As previously described [22], recruitment was performed in 1999 to 2003 by random digit dialing using households as the sampling frame. In each household identified, a resident aged 18 years or more was randomly selected for evaluation without replacement if a refusal occurred. A participation proportion of $70.0 \%$ was initially achieved and $67.7 \%$ of subjects were reevaluated during 2005 to 2008 . Of these, a subsample of 518 subjects consecutively evaluated was invited to undergo $\mathrm{X}$-ray examination. Subjects were excluded if they had instrumentation of the spine $(n=2)$, hip arthroplasty $(n=10)$, and inflammatory spinal arthropathies $(n=17)$. The final sample included 489 subjects that were evaluated by trained health professionals after a standardized protocol. The sample size allowed for the estimation of a $5 \%$ prevalence of Type 1 postural pattern, with $2 \%$ precision and $80 \%$ power, at a $95 \%$ confidence level.

The ethics committee of Hospital de São João approved the study protocol. All participants gave written informed consent to participate in the study.

\section{Sagittal spinopelvic alignment}

Radiographic data collection consisted of 36-inch standing sagittal radiographs obtained in free-standing posture, performed by one of eight radiology technicians according to routine operating procedures. All radiographic films were digitized using a Vidar scanner (Vidar Systems Corp., Herndon, VA, USA) with 75 dpi resolution and 12 gray levels and then analyzed using a spine dedicated software with a precision of $0.1^{\circ}$ in angles and $0.1 \mathrm{~mm}$ in distances (Sectra Imtec AB, Linköping, Sweden). Radiographic spinopelvic measures were recorded by a single physical therapist who was trained to the effect and remained blind regarding sociodemographic, anthropometric, and behavioral participants' characteristics. 


\section{Individual parameters}

Parameters measured included lumbar lordosis, number of vertebrae in lumbar lordosis, sagittal vertical axis (negative when posterior to the posterosuperior corner of S1), pelvic incidence, pelvic tilt, and sacral slope (Fig. 1). Lumbar lordosis and the number of vertebrae in lumbar lordosis were assessed, taking into account the point where the orientation of the spinal curvatures changed from lordosis to kyphosis (inflection point) [23]. This morphological point was defined to be located in the distal intervertebral space of the most tilted thoracolumbar vertebra. Because pelvic parameters are geometrically related [24], pelvic tilt/pelvic incidence ratio was computed to indicate the extent of pelvic retroversion for a given pelvic incidence.

\section{Postural patterns}

Sagittal postural pattern was then determined for each participant in respect to the classification by Roussouly et al. [23], based primarily on sacral slope and then on the number of vertebrae in lumbar lordosis, as recently suggested [6]. Specifically, a Type 1 was assigned if sacral slope was less than $35.5^{\circ}$ and number of vertebrae in lumbar lordosis less or equal to three; Type 2 if sacral slope was less than $35.5^{\circ}$ and number of vertebrae in lumbar lordosis more than three; Type 3 if sacral slope was between $35.5^{\circ}$ and $44.4^{\circ}$, and a Type 4 if sacral slope was higher than or equal to $44.5^{\circ}$.

Operationally, Type 3 corresponds to a balanced and neutral sagittal postural pattern, whereas others represent different nonneutral sagittal standing postures. Types 1 and 2 show a small degree of lumbar lordosis with Type 1 , representing a nonharmonious spine characterized by thoracolumbar kyphosis and short lumbar lordosis, whereas Type 2 denotes a regular flat spine presenting longer lumbar region. On the opposite extreme, Type 4 postural pattern indicates a generally hypercurved and harmonious spine [23].

\section{Sociodemographics}

Age was categorized in three groups: younger than 40 years, 40 to 64 years, and 65 years or older. Education was recorded as completed years of schooling and aggregated in three categories: up to 4 years, 5 to 9 years, 10 years or higher. Occupations were classified in major professional groups according to the National Classification of Occupations (version 1994) [25] and grouped in three categories: blue collar, lower white collar, and upper white collar. A more detailed description of each occupational group has been already published [26]. Housewives $(\mathrm{n}=46)$ were analyzed separately and six students were not considered in the occupational analysis.

\section{Anthropometrics}

Anthropometric data were obtained with participants in light indoor clothing and barefoot. Body weight was

\section{EVIDENCE \\ METHODS}

\section{Context}

The importance of sagittal balance and spino-pelvic alignment has been increasingly appreciated for a number of dimensions within the field of spine surgery. At the same time, socio-demographic and patient-based factors that may adversely influence sagittal alignment are not well understood. Using a population-based sample, the authors sought to correlate a number of factors with non-neutral posture.

\section{Contribution}

The authors illustrate the role that elevated BMI and central obesity play in increasing the risk of sagittal malalignment in individuals living in the city of Porto, Portugal.

\section{Implications}

The present study adds to the current literature by highlighting the adverse effect that obesity in general, and central obesity in particular, have on sagittal balance and posture. The ultimate impact that this reality may have on the development of spinal disorders can certainly be postulated, but cannot truly be addressed due to the cross-sectional design of this investigation. Furthermore, ethno-cultural and socio-demographic parameters unique to the demographic under consideration might impair generalization of these findings to individuals in the United States or elsewhere. Clearly, more work of this kind, longitudinal in nature, is necessary before definitive conclusions can be drawn.

- The Editors

measured to the nearest $0.1 \mathrm{Kg}$ using a digital scale (SECA, Columbia, USA), and height was measured to the nearest centimeter with a wall stadiometer (SECA, Hamburg, Germany) in standing position. Body mass index was calculated as weight (kilograms) divided by squared height (meters) and categorized in three groups: normal weight (BMI less than $25.0 \mathrm{Kg} / \mathrm{m}^{2}$ ), overweight (BMI 25.0 to $29.9 \mathrm{Kg} / \mathrm{m}^{2}$ ), and obese (BMI equal to or above $30.0 \mathrm{Kg} / \mathrm{m}^{2}$ ) [27]. Waist circumference was measured midway between the lower limit of the rib cage and the iliac crest and hip circumference was measured over the femoral trochanters, both to the nearest centimeter. Participants were standing and a flexible and nondistensible tape was used to avoid exerting pressure on tissues. Central obesity was considered present if waist circumference was higher than $102.0 \mathrm{~cm}$ for men and $88.0 \mathrm{~cm}$ for women [27].

\section{Behavioral characteristics}

Physical activity was assessed using a previously validated questionnaire [28]. Standard metabolic energy 

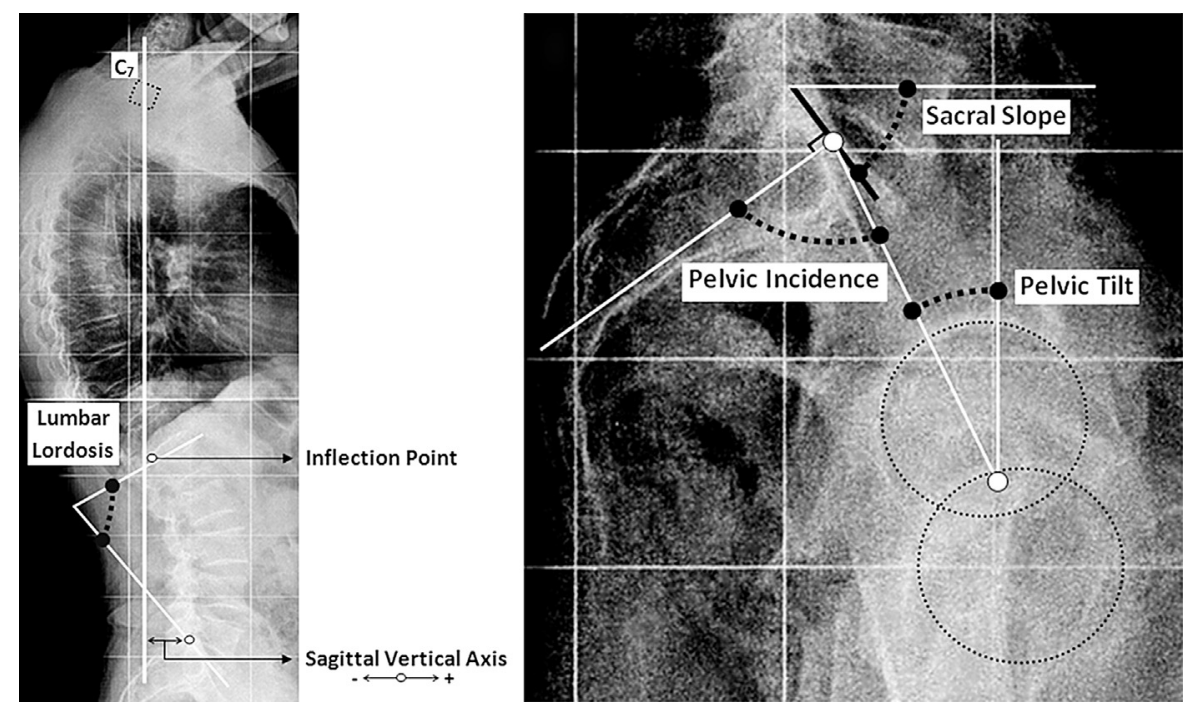

Fig. 1. Measurement technique of (Left) spinal and (Right) pelvic sagittal radiographic parameters.

equivalent task (MET) values were used to calculate energy expenditure compared with the resting metabolic rate [29]. Daily activities were classified as very light, light, moderate, and heavy intensity, corresponding to an average of $1.5,2.5,5.0$, and 7.0 MET, respectively [30]. Energy expenditure was estimated through multiplication of the corresponding MET value by the time spent in each activity. Total physical activity comprised all activities during the entire day (sleep, work, household chores, and leisure time activities), whereas leisure time physical activity included leisure time activities only (sedentary activities such as watching television and different types of exercises). Sexspecific thirds were created for total and leisure time physical activity. Participants also self-reported the average time spent per day in sitting position during leisure time, and the median of the distribution was used to classify exposure.

Participants were classified as never smokers, former smokers (having quit smoking for at least 6 months), and current smokers (including daily and occasional smokers) [31]. Tobacco consumption over the life course was calculated as the result of multiplying the average number of cigarette packs smoked per year (during the longest period of constant exposure dose) by the number of smoking years. Categorization was then performed: never smokers, lower and higher tobacco consumption (cutoff based on the median of the distribution among those who had ever smoked).

\section{Statistical analysis}

Descriptive data for radiographic spinopelvic parameters were reported as median (25th percentile, 75 th percentile). The statistical significance of differences in radiographic parameters between categories of participants' characteristics was assessed through Mann-Whitney or Kruskal-Wallis tests (as appropriate) and between types of sagittal postural patterns through the Kruskal-Wallis test.
Multinomial logistic regression was performed using as outcome a dependent variable with four categories, each corresponding to one of the four postural patterns. Crude and adjusted odds ratios (OR) with $95 \%$ confidence intervals (95\% CI) were estimated to quantify the associations of sociodemographic, anthropometric, and behavioral characteristics with each of the three nonneutral sagittal postural patterns (Types 1, 2, and 4), having always Type 3 (neutral) as reference category. Associations were adjusted for age, sex, education, BMI, total physical activity, and smoking status.

\section{Results}

Table 1 describes individual radiographic parameters according to categories of each sociodemographic, anthropometric, and behavioral characteristics. Median pelvic incidence was $3.9^{\circ}$ higher in less educated participants than in those presenting the highest educational level. Sagittal balance was more anteriorly displaced in older adults and among those with lower level of formal education or blue collar occupations. Sagittal vertical axis was also higher in participants with central obesity, among those in the 1st third of total physical activity or reporting longer periods spent in sitting position. Although no statistical difference was observed between groups, blue collar workers and overall and centrally-obese participants presented a higher median pelvic incidence and obesity was related with greater sagittal vertical axis. All of the previous characteristics, except for total physical activity and time spent in sitting position, were significantly associated with higher median pelvic tilt/pelvic incidence ratio.

The prevalence of Type 1,2,3, and 4 postural patterns was $4.9 \%, 31.3 \%, 42.3 \%$, and $21.5 \%$, respectively. Descriptive data relating to radiographic sagittal spinopelvic parameters in the types of postural patterns are shown 
Table 1

Median (25th percentile, 75th percentile) of radiographic sagittal spinopelvic parameters according to categories of sociodemographic, anthropometric, and behavioral characteristics

\begin{tabular}{|c|c|c|c|c|c|c|c|c|c|c|c|c|c|}
\hline Characteristics & $\begin{array}{l}\text { All participants, } \\
\mathrm{n}(\%)\end{array}$ & Pelvic incidence & $\mathrm{p}$ & Pelvic tilt & $\mathrm{p}$ & Sacral slope & $\mathrm{p}$ & Lumbar lordosis & $\mathrm{p}$ & Sagittal vertical axis & $\mathrm{p}$ & $\begin{array}{l}\text { Pelvic tilt/pelvic } \\
\text { incidence ratio }\end{array}$ & $\mathrm{p}$ \\
\hline All participants $(n=489)$ & & $54.1(46.6,62.6)$ & & $15.8(11.2,21.1)$ & & $38.7(32.8,43.7)$ & & $61.6(54.5,69.2)$ & & $-15.9(-38.8,6.2)$ & & $0.29(0.23,0.36)$ & \\
\hline \multicolumn{14}{|l|}{ Sociodemographic } \\
\hline \multicolumn{14}{|l|}{ Age, y $(n=489)$} \\
\hline$<40$ & $57(11.7)$ & $55.4(44.9,63.8)$ & \multirow[t]{3}{*}{.139} & $15.2(9.0,21.0)$ & \multirow[t]{3}{*}{.001} & $39.8(34.2,45.2)$ & \multirow[t]{3}{*}{.167} & $64.0(57.0,71.2)$ & \multirow[t]{3}{*}{.184} & $-39.6(-59.7,-20.1)$ & \multirow[t]{3}{*}{$<.001$} & $0.27(0.19,0.33)$ & \multirow[t]{3}{*}{$<.001$} \\
\hline $40-64$ & $238(48.7)$ & $51.8(45.8,61.8)$ & & $14.9(10.6,19.6)$ & & $39.1(32.9,43.2)$ & & $61.5(54.5,68.3)$ & & $-26.3(-47.0,-7.5)$ & & $0.28(0.22,0.35)$ & \\
\hline$\geq 65$ & $194(39.7)$ & $55.4(47.5,63.1)$ & & $17.0(12.5,22.6)$ & & $37.7(32.0,43.9)$ & & $61.2(53.2,68.8)$ & & $2.1(-18.2,23.0)$ & & $0.32(0.25,0.38)$ & \\
\hline \multicolumn{14}{|l|}{$\operatorname{Sex}(n=489)$} \\
\hline Men & $178(36.4)$ & $54.1(47.0,62.3)$ & \multirow[t]{2}{*}{.693} & $15.9(11.3,19.9)$ & \multirow[t]{2}{*}{.586} & $38.7(32.6,44.3)$ & \multirow[t]{2}{*}{.838} & $61.0(54.5,68.7)$ & \multirow[t]{2}{*}{.603} & $-14.9(-36.9,6.68)$ & \multirow[t]{2}{*}{.508} & $0.29(0.23,0.35)$ & \multirow[t]{2}{*}{.602} \\
\hline Women & $311(63.6)$ & $54.1(45.9,63.1)$ & & $15.6(11.1,21.8)$ & & $38.8(33.2,43.3)$ & & $62.1(54.6,69.4)$ & & $-16.8(-39.9,5.7)$ & & $0.29(0.22,0.36)$ & \\
\hline \multicolumn{14}{|l|}{ Education, y $(\mathrm{n}=489)$} \\
\hline$\leq 4$ & $184(37.6)$ & $56.4(48.3,65.0)$ & \multirow[t]{3}{*}{.006} & $17.0(12.5,22.8)$ & \multirow[t]{3}{*}{.001} & $39.6(32.9,44.1)$ & \multirow[t]{3}{*}{.272} & $61.6(54.1,71.0)$ & \multirow[t]{3}{*}{.567} & $-6.3(-26.3,15.5)$ & \multirow[t]{3}{*}{$<.001$} & $0.31(0.24,0.38)$ & \multirow[t]{3}{*}{.015} \\
\hline $5-9$ & $137(28.0)$ & $52.6(44.5,59.4)$ & & $15.2(10.6,19.6)$ & & $37.4(31.5,43.5)$ & & $60.9(52.6,68.3)$ & & $-24.3(-42.8,3.0)$ & & $0.28(0.22,0.35)$ & \\
\hline$\geq 10$ & $168(34.4)$ & $52.5(45.0,63.0)$ & & $15.3(9.7,20.2)$ & & $39.2(33.5,43.6)$ & & $63.2(55.2,68.6)$ & & $-26.3(-48.3,-5.9)$ & & $0.29(0.22,0.36)$ & \\
\hline \multicolumn{14}{|l|}{ Occupation $(n=483)^{*}$} \\
\hline Blue collar & $147(30.4)$ & $56.1(48.7,64.9)$ & .052 & $16.7(12.9,22.9)$ & .016 & $39.7(33.7,44.6)$ & .361 & $63.3(54.6,70.3)$ & .414 & $-8.1(-32.1,12.0)$ & .002 & $0.32(0.24,0.37)$ & .048 \\
\hline Lower white collar & $133(27.5)$ & $53.1(43.8,62.3)$ & & $15.0(10.7,20.0)$ & & $38.9(32.7,43.1)$ & & $61.1(54.1,70.1)$ & & $-19.8(-47.7,9.3)$ & & $0.28(0.22,0.35)$ & \\
\hline Upper white collar & $157(32.5)$ & $52.6(46.1,61.2)$ & & $15.3(10.1,20.1)$ & & $38.0(33.1,43.6)$ & & $62.1(54.9,67.8)$ & & $-25.2(-43.2,-0.2)$ & & $0.29(0.22,0.36)$ & \\
\hline Housewives & $46(9.5)$ & $53.9(44.7,58.4)$ & & $16.1(11.1,21.1)$ & & $37.1(29.8,42.9)$ & & $58.8(49.2,68.6)$ & & $-11.7(-33.2,7.9)$ & & $0.32(0.21,0.37)$ & \\
\hline Anthropometrics & & & & & & & & & & & & & \\
\hline BMI $(\mathrm{n}=489)^{\dagger}$ & & & & & & & & & & & & & \\
\hline Normal weight & $170(34.8)$ & $52.2(46.5,59.4)$ & .141 & $14.2(8.38,18.1)$ & $<.001$ & $39.2(34.5,43.5)$ & .503 & $61.9(54.9,69.5)$ & .644 & $-25.2(-44.8,4.1)$ & .067 & $0.26(0.19,0.33)$ & $<.001$ \\
\hline Overweight & $211(43.1)$ & $54.4(45.9,63.3)$ & & $16.5(12.2,22.4)$ & & $38.3(32.1,43.9)$ & & $61.4(53.7,68.4)$ & & $-14.7(-36.6,8.1)$ & & $0.32(0.26,0.37)$ & \\
\hline Obese & $108(22.1)$ & $56.5(46.6,64.4)$ & & $17.1(12.3,22.4)$ & & $38.6(31.3,42.6)$ & & $61.8(54.7,71.2)$ & & $-13.1(-34.7,4.4)$ & & $0.31(0.24,0.38)$ & \\
\hline $\begin{array}{l}\text { Waist circumference } \\
\qquad(\mathrm{n}=487)^{\ddagger}\end{array}$ & & & & & & & & & & & & & \\
\hline No central obesity & $287(58.9)$ & $53.2(45.0,61.0)$ & .068 & $15.1(10.0,19.5)$ & $<.001$ & $39.1(33.4,43.9)$ & .395 & $61.9(54.7,69.2)$ & .966 & $-22.2(-42.9,1.8)$ & $<.001$ & $0.28(0.21,0.35)$ & $<.001$ \\
\hline Central obesity & $200(41.1)$ & $55.0(47.6,64.0)$ & & $17.2(12.5,22.7)$ & & $38.5(31.9,43.1)$ & & $61.4(53.9,69.1)$ & & $-10.4(-31.9,11.6)$ & & $0.32(0.25,0.39)$ & \\
\hline Behavioral & & & & & & & & & & & & & \\
\hline Total PA $(\mathrm{n}=430)^{\S}$ & & & & & & & & & & & & & \\
\hline 1st third & $133(30.9)$ & $53.9(45.1,60.1)$ & .763 & $15.4(11.4,20.9)$ & 991 & $37.9(31.1,44.0)$ & .528 & $61.8(53.3,68.0)$ & .397 & $-10.5(-36.9,10.8)$ & .010 & $0.30(0.23,0.37)$ & .543 \\
\hline 2nd third & $158(36.7)$ & $54.8(46.6,62.3)$ & & $15.8(11.2,20.0)$ & & $39.0(33.7,43.4)$ & & $62.1(55.1,69.5)$ & & $-15.6(-39.7,7.5)$ & & $0.28(0.22,0.35)$ & \\
\hline 3rd third & $139(32.3)$ & $53.0(45.9,63.6)$ & & $15.6(10.8,20.9)$ & & $39.0(32.7,43.5)$ & & $61.4(54.7,68.6)$ & & $-23.7(-43.5,-7.2)$ & & $0.30(0.23,0.36)$ & \\
\hline Leisure time PA $(n=4$ & $3)^{\pi}$ & & & & & & & & & & & & \\
\hline 1st third & $135(28.0)$ & $53.2(47.0,63.7)$ & .345 & $16.1(11.8,21.0)$ & 117 & $40.0(32.8,43.9)$ & .597 & $63.0(54.9,71.4)$ & .274 & $-21.6(-43.5,-3.3)$ & .038 & $0.30(0.23,0.35)$ & .226 \\
\hline 2nd third & $188(38.9)$ & $52.9(45.8,60.9)$ & & $15.2(10.5,20.6)$ & & $38.4(32.5,43.4)$ & & $61.6(53.3,68.4)$ & & $-19.2(-40.5,4.7)$ & & $0.29(0.21,0.36)$ & \\
\hline 3rd third & $160(33.1)$ & $55.5(46.8,63.0)$ & & $16.3(11.5,21.8)$ & & $38.6(33.4,44.1)$ & & $61.3(53.4,67.6)$ & & $-11.6(-34.7,10.7)$ & & $0.30(0.24,0.36)$ & \\
\hline Sitting position $(\mathrm{n}=48$ & & & & & & & & & & & & & \\
\hline $\begin{array}{l}\text { Below or at the } \\
\text { median }\end{array}$ & $248(50.9)$ & $53.2(45.9,63.3)$ & .851 & $15.3(10.8,20.2)$ & .140 & $39.5(33.3,43.9)$ & .187 & $62.3(55.4,70.4)$ & .060 & $-21.6(-43.4,-1.5)$ & .002 & $0.29(0.22,0.35)$ & .065 \\
\hline Above the median & $239(49.1)$ & $54.9(47.0,62.1)$ & & $16.2(11.4,21.6)$ & & $38.1(32.0,43.4)$ & & $61.1(52.5,67.5)$ & & $-12.0(-34.5,9.9)$ & & $0.30(0.23,0.36)$ & \\
\hline
\end{tabular}




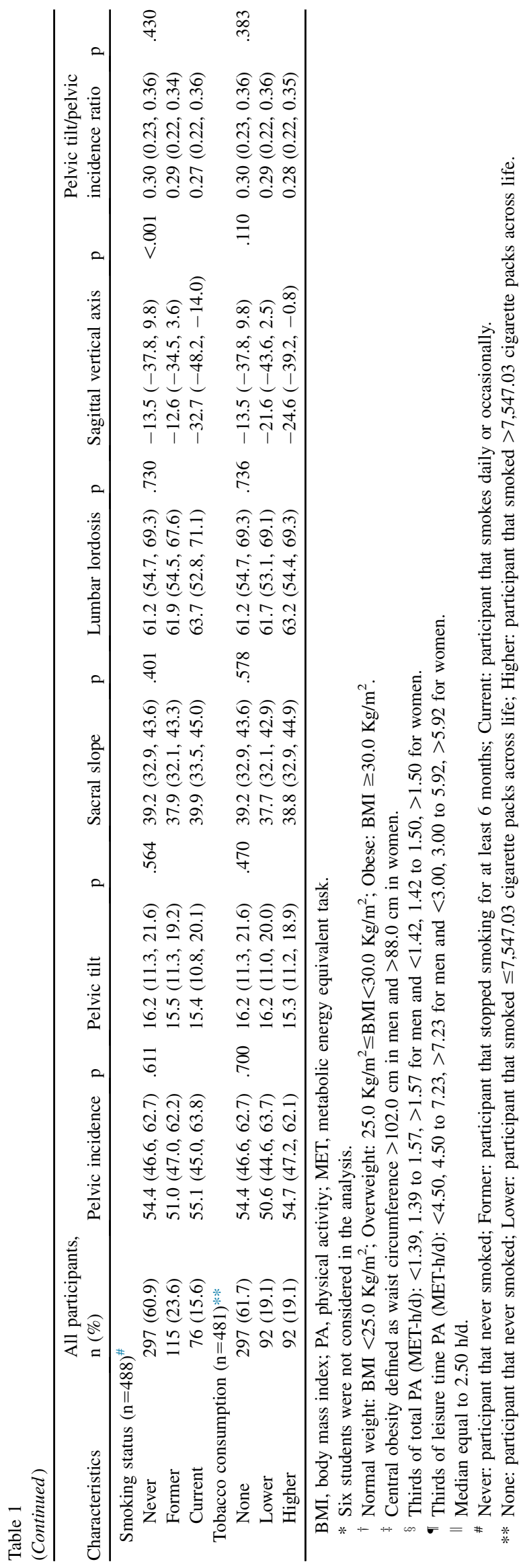

in Table 2 and examples of each pattern are displayed using sample participants' radiographs in Fig. 2. Type 1 postural pattern had the smallest median sacral slope, lumbar lordosis, and number of vertebrae in lumbar lordosis, but the highest median pelvic tilt and pelvic tilt/pelvic incidence ratio.

The proportions of nonneutral postural patterns within categories of selected sociodemographic, anthropometric, and behavioral characteristics are displayed in Fig. 3. Table 3 shows the associations between participants' characteristics and nonneutral postural patterns when compared with the neutral pattern (Type 3) between categories of the explanatory variables considered in the regression model. Overweight adults had higher crude and adjusted odds of Type 2 pattern (vs. Type 3) than normal weight subjects (adjusted $\mathrm{OR}=1.92 ; 95 \% \mathrm{CI}: 1.13-3.27$ ). The association of overweight with Type 4 postural pattern (vs. Type 3) was statistically significant when adjusted for other characteristics. Being obese (adjusted OR $=6.10$; 95\% CI: $1.52-$ 24.57) and presenting central obesity (adjusted $\mathrm{OR}=3.54$; 95\% CI: 1.13-11.11) were positively related with Type 1 postural pattern (vs. Type 3), but no statistical relation was observed with Type 2 or 4 patterns.

Female sex was associated with Type 1 with borderline significance (crude OR $=3.42$; 95\% CI: 0.99-11.88), even when adjusted for sociodemographic, anthropometric, and behavioral characteristics. Although nonsignificantly, subjects in the 2nd and 3rd thirds of total physical activity had lower adjusted odds of exhibiting all nonneutral postural patterns, 0.35 and 0.69 in Type 1, 0.61 and 0.64 in Type 2 , and 0.64 and 0.59 in Type 4, respectively. When adjusted for other sociodemographic, anthropometric, and behavioral characteristics, current smokers presented slightly higher odds of Type 4 postural pattern in comparison with never smokers $(\mathrm{OR}=2.09$; 95\% CI: 0.97-4.48).

\section{Discussion}

In this population-based survey of frequency and correlates of suboptimal alignment of standing posture, we observed that older age, lower socioeconomic status, and overall and central obesity were associated with higher anterior displacement of sagittal balance, with consequent increase in compensatory pelvic retroversion. Body mass index and central obesity were the characteristics more strongly associated with nonneutral postural patterns.

It is believed that mechanical constraints imposed by higher BMI in the first years of life could explain the positive association of BMI with pelvic incidence, sacral slope, and lumbar lordosis in adults [19] and with hyperlordotic or sway standing postures in adolescents [32]. We have found a slight pelvic incidence increase with increased BMI categories, although overweight and obesity were associated with higher compensatory pelvic retroversion leading to a more extreme nonneutral posture of small 
Table 2

Radiographic sagittal spinopelvic parameters in types of postural patterns*

\begin{tabular}{|c|c|c|c|c|c|}
\hline \multirow[b]{2}{*}{ Parameters } & \multicolumn{4}{|l|}{ Sagittal postural pattern } & \multirow[b]{2}{*}{$\mathrm{p}$} \\
\hline & Type $1(n=24[4.9 \%])$ & Type $2(n=153[31.3 \%])$ & Type $3(n=207[42.3 \%])$ & Type $4(\mathrm{n}=105[21.5 \%])$ & \\
\hline Pelvic incidence, ${ }^{\circ}$ & $46.5(37.5,54.7)$ & $44.7(39.7,50.0)$ & $55.4(50.0,60.3)$ & $67.5(62.3,75.0)$ & $<.001$ \\
\hline Sacral slope, ${ }^{\circ}$ & $27.4(24.7,32.1)$ & $30.6(27.6,33.4)$ & $40.2(38.2,42.1)$ & $48.4(45.9,51.3)$ & $<.001$ \\
\hline Lumbar lordosis, ${ }^{\circ}$ & $44.4(38.3,49.6)$ & $53.7(48.1,58.8)$ & $63.3(58.4,67.7)$ & $73.3(68.3,80.0)$ & $<.001$ \\
\hline Vertebrae in lumbar lordosis & $3.0(3.0,3.0)$ & $5.0(4.0,5.0)$ & $5.0(4.0,5.0)$ & $5.0(4.0,6.0)$ & $<.001$ \\
\hline Sagittal vertical axis, mm & $-4.4(-20.0,26.6)$ & $-19.2(-39.9,-3.9)$ & $-18.9(-40.5,4.8)$ & $-14.7(-37.5,12.3)$ & .068 \\
\hline
\end{tabular}

* Values are reported as median (25th percentile, 75 th percentile).

lumbar lordosis (Types 1 or 2). Overweight but not obesity was also associated with Type 4 postural pattern. This possibly denotes a natural tendency for adiposity to be related with a hypercurved spine. As adiposity increases, this effect may be surpassed by pelvic adaptations that result in an exclusive association between obesity and the Type 1 pattern - the most hypolordotic and unique nonharmonious posture. The increased compensatory pelvic retroversion observed in overall and central obesity among adults may act as a cause or a consequence of previously described higher functional limitations and disability in those subjects $[33,34]$. The causal role of adiposity (general and central) in anteriorly displacing sagittal balance remains to be clarified, namely regarding the temporal sequence of the events and the mechanisms underlying the nonlinear association between BMI categories and postural patterns. Although the relation between adiposity and nonneutral postural patterns was evident in our analyses, a previous study has reported a similar distribution of postural patterns across BMI categories [18], but different measurement technique, sample selection, ethnical background, and mainly lower statistical power could potentially explain the observed lack of association.

It seems noteworthy that total and leisure time physical activity were not clearly associated with sagittal posture. However, subjects in the two highest thirds of total physical activity could be protected from nonneutral postural patterns, even though nonsignificantly. Previous evidence shows that minimal levels of physical activity could prevent the deterioration of strength, balance, and bone mineral density [35-37] and sedentariness may cause loss of back extensor strength that could lead to increased thoracic kyphosis [38,39] or decreased lumbar lordosis [38,39] and sacral slope [39]. Additionally, the effect of physical activity on adiposity is a probable intermediate link in the path between minimal levels of activity and lower frequency of nonneutral postural patterns. However, the magnitude of our association between physical activity and postural patterns was independent of BMI adjustment, which probably means that other causal pathways may exist. However,
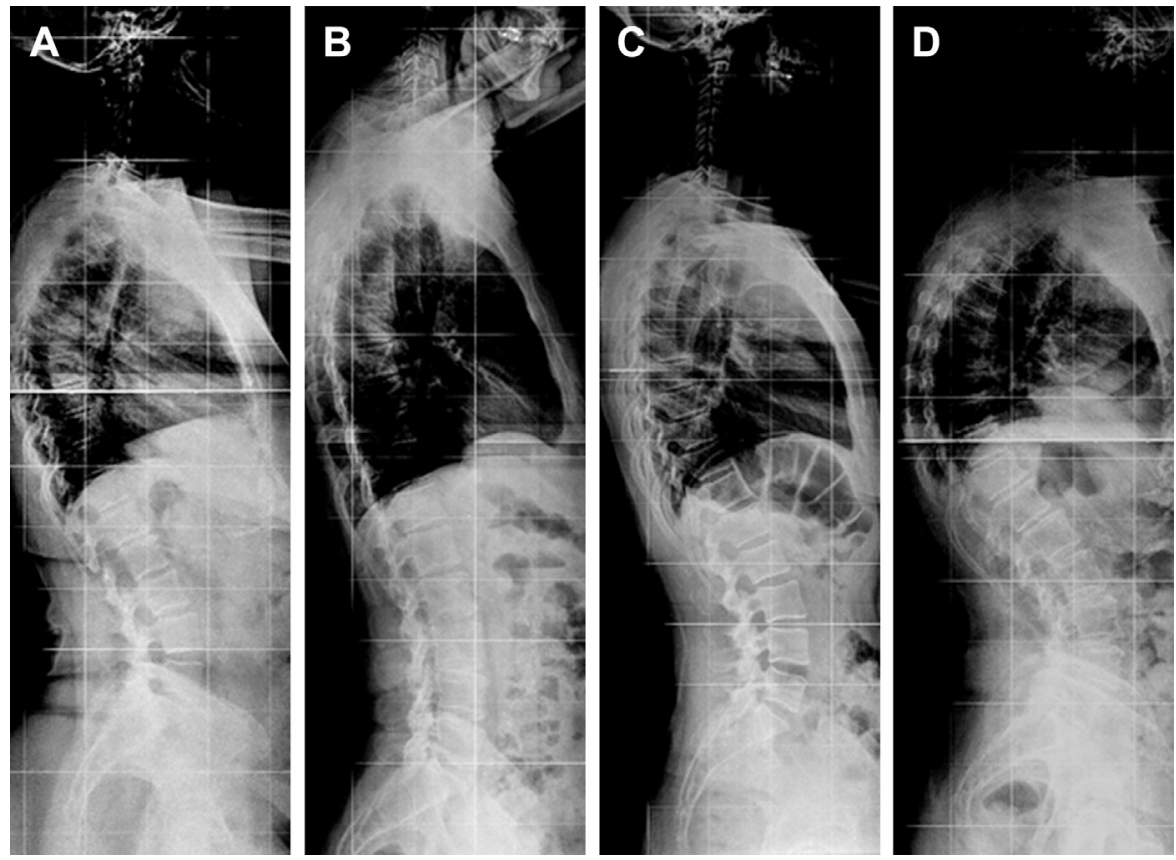

Fig. 2. Sagittal spinopelvic alignment in each postural pattern (Roussouly classification): (A) Type 1, (B) Type 2, (C) Type 3: neutral, and (D) Type 4. 
Age (years)

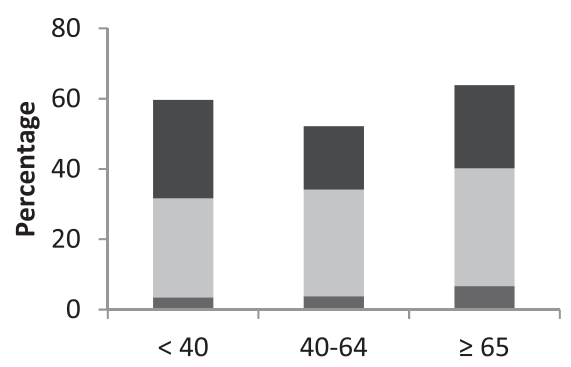

Education (years)

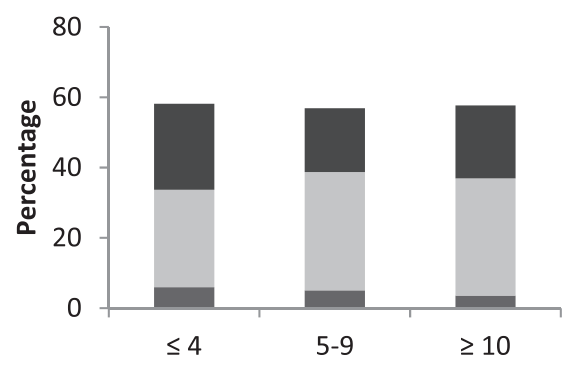

Body mass index

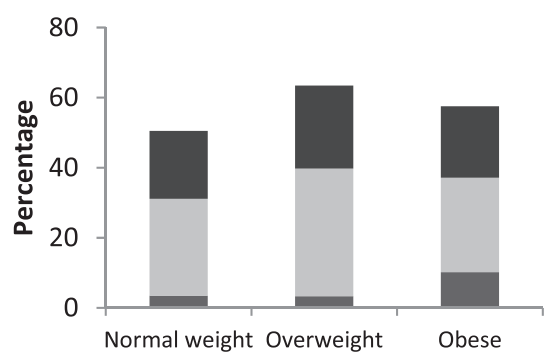

Total physical activity

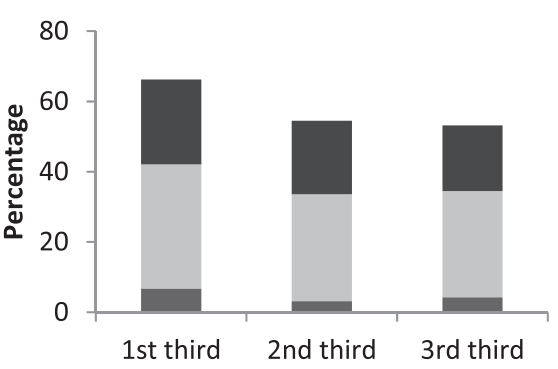

Sex

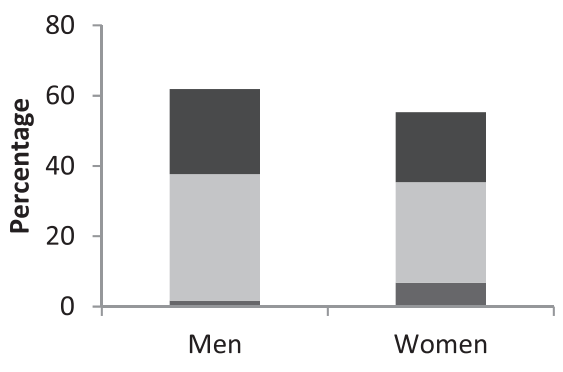

Occupation

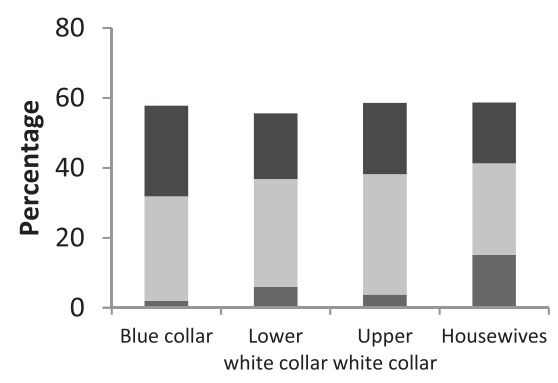

Central obesity

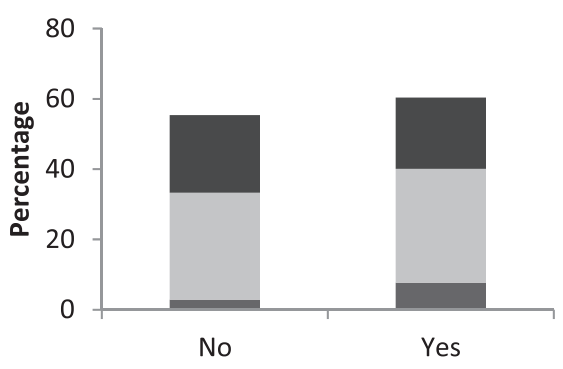

Leisure time physical activity

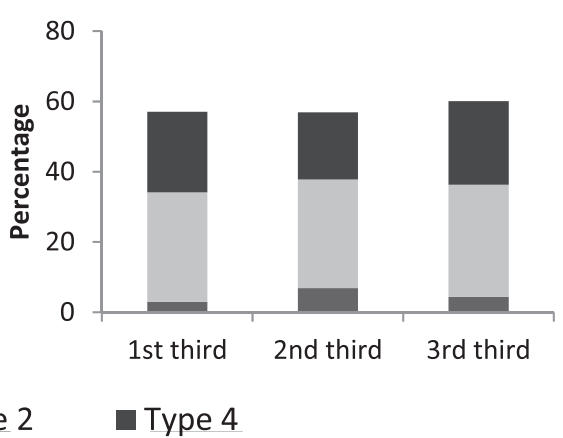

Fig. 3. Proportions of nonneutral sagittal postural patterns within categories of selected sociodemographic, anthropometric, and behavioral characteristics.

because of the expected lag time between exposure to physical activity and the postural outcome, the direction of the relation between physical activity levels and postural patterns could only be confirmed through prospective evidence, which is out of the scope of the present crosssectional study.

To compensate for age-related changes in spine with progressive anterior balance $[14,16]$, it is expected that pelvic retroversion increases, affecting sagittal spinopelvic alignment $[14,40]$. We have confirmed those results, albeit without translating into changes in postural patterns. This is in accordance with previous studies that reported only modest postural adaptations with aging $[13,15]$, without an effect in overall sagittal posture [18].

No differences were found between sexes regarding individual parameters of sagittal posture as reported by most 
Table 3

Crude and adjusted associations of sociodemographic, anthropometric, and behavioral characteristics with nonneutral sagittal postural patterns

\begin{tabular}{|c|c|c|c|c|c|c|}
\hline \multirow[b]{3}{*}{ Characteristics } & \multicolumn{6}{|c|}{ Sagittal postural pattern } \\
\hline & \multicolumn{2}{|l|}{ Type 1} & \multicolumn{2}{|l|}{ Type 2} & \multicolumn{2}{|l|}{ Type 4} \\
\hline & $\begin{array}{l}\text { Crude } \\
\text { OR }(95 \% \mathrm{CI})\end{array}$ & $\begin{array}{l}\text { Adjusted } \\
\text { OR }(95 \% \mathrm{CI})^{*}\end{array}$ & $\begin{array}{l}\text { Crude } \\
\text { OR }(95 \% \mathrm{CI})\end{array}$ & $\begin{array}{l}\text { Adjusted } \\
\text { OR }(95 \% \mathrm{CI})^{*}\end{array}$ & $\begin{array}{l}\text { Crude } \\
\text { OR }(95 \% \text { CI })\end{array}$ & $\begin{array}{l}\text { Adjusted } \\
\text { OR }(95 \% \text { CI })^{*}\end{array}$ \\
\hline \multicolumn{7}{|l|}{ Sociodemographic } \\
\hline \multicolumn{7}{|l|}{ Age, y $(n=489)$} \\
\hline$<40$ & 1.00 & 1.00 & 1.00 & 1.00 & 1.00 & 1.00 \\
\hline $40-64$ & $0.91(0.18-4.48)$ & $0.32(0.05-1.97)$ & $0.91(0.45-1.83)$ & $0.80(0.36-1.77)$ & $0.54(0.26-1.12)$ & $0.45(0.19-1.06)$ \\
\hline$\geq 65$ & $2.14(0.45-10.18)$ & $1.31(0.19-9.25)$ & $1.34(0.65-2.75)$ & $1.25(0.51-3.05)$ & $0.95(0.45-1.98)$ & $0.80(0.30-2.12)$ \\
\hline \multicolumn{7}{|l|}{$\operatorname{Sex}(n=489)$} \\
\hline Men & 1.00 & 1.00 & 1.00 & 1.00 & 1.00 & 1.00 \\
\hline Women & $3.42(0.99-11.88)$ & $4.09(0.81-20.7)$ & $0.68(0.44-1.05)$ & $0.83(0.49-1.40)$ & $0.71(0.43-1.15)$ & $0.83(0.46-1.51)$ \\
\hline \multicolumn{7}{|l|}{ Education, y $(\mathrm{n}=489)$} \\
\hline$\leq 4$ & 1.00 & 1.00 & 1.00 & 1.00 & 1.00 & 1.00 \\
\hline $5-9$ & $0.83(0.30-2.27)$ & $2.56(0.76-8.68)$ & $1.18(0.70-1.99)$ & $1.33(0.72-2.46)$ & $0.73(0.40-1.32)$ & $0.88(0.44-1.75)$ \\
\hline$\geq 10$ & $0.59(0.21-1.68)$ & $1.11(0.24-5.10)$ & $1.19(0.72-1.96)$ & $1.46(0.79-2.71)$ & $0.84(0.49-1.46)$ & $0.86(0.42-1.74)$ \\
\hline \multicolumn{7}{|l|}{ Occupation $(\mathrm{n}=483)^{\dagger}$} \\
\hline Blue collar & 1.00 & 1.00 & 1.00 & 1.00 & 1.00 & 1.00 \\
\hline Lower white collar & $2.80(0.71-11.07)$ & $6.94(1.20-40.07)$ & $1.00(0.56-1.71)$ & $1.00(0.51-1.95)$ & $0.69(0.37-1.28)$ & $0.61(0.28-1.31)$ \\
\hline Upper white collar & $1.91(0.46-7.96)$ & $4.85(0.57-41.28)$ & $1.17(0.69-1.99)$ & $1.22(0.53-2.83)$ & $0.80(0.45-1.44)$ & $0.95(0.36-2.47)$ \\
\hline Housewives & $7.61(1.79-32.36)$ & $9.25(1.50-57.15)$ & $0.89(0.39-2.02)$ & $0.84(0.32-2.22)$ & $0.69(0.27-1.72)$ & $0.68(0.23-1.98)$ \\
\hline \multicolumn{7}{|l|}{ Anthropometrics } \\
\hline \multicolumn{7}{|l|}{ BMI $(\mathrm{n}=489)^{\ddagger}$} \\
\hline Normal weight & 1.00 & 1.00 & 1.00 & 1.00 & 1.00 & 1.00 \\
\hline Overweight & $1.27(0.41-3.95)$ & $2.22(0.55-8.97)$ & $1.79(1.11-2.88)$ & $1.92(1.13-3.27)$ & $1.65(0.97-2.83)$ & $2.13(1.16-3.91)$ \\
\hline Obese & $3.35(1.16-9.64)$ & $6.10(1.52-24.57)$ & $1.13(0.63-2.03)$ & $1.41(0.72-2.75)$ & $1.22(0.64-2.33)$ & $1.51(0.70-3.25)$ \\
\hline \multicolumn{7}{|c|}{ Waist circumference $(\mathrm{n}=487)^{\S}$} \\
\hline No central obesity & 1.00 & 1.00 & 1.00 & 1.00 & 1.00 & 1.00 \\
\hline Central obesity & $3.11(1.27-7.60)$ & $3.54(1.13-11.11)$ & $1.04(0.68-1.60)$ & $1.20(0.71-2.01)$ & $1.05(0.65-1.71)$ & $1.33(0.73-2.41)$ \\
\hline \multicolumn{7}{|l|}{ Behavioral } \\
\hline \multicolumn{7}{|l|}{ Total PA $(n=430)^{\pi}$} \\
\hline 1st third & 1.00 & 1.00 & 1.00 & 1.00 & 1.00 & 1.00 \\
\hline 2nd third & $0.35(0.11-1.10)$ & $0.35(0.10-1.16)$ & $0.64(0.37-1.10)$ & $0.61(0.35-1.06)$ & $0.65(0.35-1.19)$ & $0.64(0.34-1.19)$ \\
\hline 3rd third & $0.46(0.15-1.39)$ & $0.69(0.20-2.46)$ & $0.62(0.35-1.09)$ & $0.64(0.35-1.17)$ & $0.56(0.30-1.07)$ & $0.59(0.29-1.18)$ \\
\hline \multicolumn{7}{|l|}{ Leisure time PA $(\mathrm{n}=483)^{\|}$} \\
\hline 1st third & 1.00 & 1.00 & 1.00 & 1.00 & 1.00 & 1.00 \\
\hline 2nd third & $2.33(0.72-7.50)$ & $1.94(0.53-7.09)$ & $0.99(0.59-1.67)$ & $0.88(0.49-1.56)$ & $0.83(0.46-1.50)$ & $0.71(0.37-1.38)$ \\
\hline 3rd third & $1.59(0.44-5.70)$ & $0.75(0.15-3.65)$ & $1.10(0.64-1.89)$ & $0.98(0.53-1.82)$ & $1.11(0.61-2.01)$ & $1.07(0.53-2.13)$ \\
\hline \multicolumn{7}{|l|}{ Sitting position $(n=487)^{\#}$} \\
\hline Below or at the median & 1.00 & 1.00 & 1.00 & 1.00 & 1.00 & 1.00 \\
\hline Above the median & $1.74(0.74-4.09)$ & $1.52(0.54-4.31)$ & $1.38(0.90-2.10)$ & $1.43(0.88-2.34)$ & $1.26(0.79-2.02)$ & $1.17(0.67-2.05)$ \\
\hline \multicolumn{7}{|l|}{ Smoking status $(\mathrm{n}=488)^{* *}$} \\
\hline Never & 1.00 & 1.00 & 1.00 & 1.00 & 1.00 & 1.00 \\
\hline Former & $0.68(0.22-2.11)$ & $0.68(0.13-3.61)$ & $1.58(0.96-2.60)$ & $1.17(0.65-2.13)$ & $1.17(0.65-2.10)$ & $1.06(0.52-2.16)$ \\
\hline Current & $0.51(0.11-2.34)$ & $1.78(0.31-10.20)$ & $1.25(0.68-2.30)$ & $1.28(0.63-2.59)$ & $1.69(0.90-3.19)$ & $2.09(0.97-4.48)$ \\
\hline \multicolumn{7}{|c|}{ Tobacco consumption $(n=481)^{\dagger \dagger}$} \\
\hline None & 1.00 & 1.00 & 1.00 & 1.00 & 1.00 & 1.00 \\
\hline Lower & $0.85(0.27-2.68)$ & $0.88(0.17-4.68)$ & $1.58(0.92-2.71)$ & $1.38(0.73-2.59)$ & $1.15(0.60-2.19)$ & $1.28(0.61-2.69)$ \\
\hline Higher & $0.21(0.03-1.65)$ & $0.61(0.07-5.64)$ & $1.40(0.80-2.43)$ & $1.17(0.60-2.29)$ & $1.60(0.88-2.90)$ & $1.80(0.86-3.78)$ \\
\hline
\end{tabular}

OR, odds ratio; CI, confidence interval; BMI, body mass index; PA, physical activity; MET, metabolic energy equivalent task.

Note: Bold type indicates statistical significance.

* Adjusted for age, sex, education, BMI, total PA, and smoking status, except in waist circumference (not adjusted for BMI) and in tobacco consumption (not adjusted for smoking status).

${ }^{\dagger}$ Six students were not considered in the analysis.

$\ddagger$ Normal weight: BMI $<25.0 \mathrm{Kg} / \mathrm{m}^{2}$; Overweight: $25.0 \mathrm{Kg} / \mathrm{m}^{2} \leq \mathrm{BMI}<30.0 \mathrm{Kg} / \mathrm{m}^{2}$; Obese: $\mathrm{BMI} \geq 30.0 \mathrm{Kg} / \mathrm{m}^{2}$.

$\S$ Central obesity defined as waist circumference $>102.0 \mathrm{~cm}$ in men and $>88.0 \mathrm{~cm}$ in women.

I Thirds of total PA (MET-h/d): $<1.39,1.39$ to $1.57,>1.57$ for men and $<1.42,1.42$ to $1.50,>1.50$ for women.

$\|$ Thirds of leisure time PA (MET-h/d): $<4.50,4.50$ to $7.23,>7.23$ for men and $<3.00,3.00$ to $5.92,>5.92$ for women.

\# Median equal to $2.50 \mathrm{~h} / \mathrm{d}$.

** Never: participant that never smoked; Former: participant that stopped smoking for at least 6 months; Current: participant that smokes daily or occasionally.

${ }^{\dagger \dagger}$ None: participant that never smoked; Lower: participant that smoked $\leq 7,547.03$ cigarette packs across life; Higher: participant that smoked $>7,547.03$ cigarette packs across life. 
of the previous studies relatively to lumbopelvic alignment $[6,7,15-17,19]$. Despite this, it was proposed that men show more frequently a postural pattern characterized by attenuated curvatures of the spine (our Type 2), both in adults [18] and adolescents [20]. However, our results show that, when comparing with the frequency of neutral posture among sexes, there are no differences in the odds between men and women regarding presenting a Type 2 postural pattern.

Individuals in lower socioeconomic groups (formal education and occupation) showed higher pelvic incidence, possibly reflecting the role of environmental influences during early stages of life in defining adult posture, as was previously suggested regarding BMI effect [19,32]. Not surprisingly, lower socioeconomic status was also associated with a more anterior displacement of sagittal balance and higher pelvic retroversion, in line with the association of poorer contextual socioeconomic conditions with worse physical performance, namely regarding standing balance $[35,41]$.

Current smokers had higher odds of accentuated sagittal curvatures of the spine (Type 4) independent of other sociodemographic, anthropometric, and behavioral characteristics. Although mechanisms are not fully understood, smoking habits have been suggested to negatively influence strength and physical performance $[42,43]$ and could increase muscle fatigability [44]. Smoking is a risk factor for osteoporosis [45], and decreased bone mineral density causes spinal structural changes that promote disc degeneration and anterior vertebral wedging that result in increased thoracic kyphosis $[46,47]$ and, then, may affect alignment of other spinopelvic regions.

Sagittal postural patterns described in our study have the expected sagittal spinopelvic alignment in accordance with Roussouly classification [23]. Nevertheless, higher compensatory pelvic retroversion was observed in Types 1 and 2 postural patterns, possibly denoting that pelvic postural adaptations occurred in our general adult sample. Given that pelvic tilt and sacral slope are inversely related [24], such changes would leave those subjects to specifically exhibit these two adaptative postural patterns of smaller sacral slope.

Neutral postural pattern (Type 3) was the most prevalent in our study $(42.3 \%)$, and prevalence estimates are between those reported in asymptomatic volunteers and low back pain patients [6], likely reflecting the case-mix occurring in the source population of our study sample.

The present study provides unique information contributing to the comprehension of the complex nonneutral standing postures among adults. Nevertheless, some limitations need to be considered. The cross-sectional nature of this study precludes the establishment of a temporal sequence in the relation between participants' characteristics and sagittal spinopelvic alignment, requiring the judgment of potential reverse causation by which sagittal posture may itself determine characteristics, such as occupation, BMI, and physical activity.
The subject's position for radiographic acquisition was standardized according to routine operating procedures in a clinical setting, and interexaminer variability between radiology technicians is expected. However, all radiology technicians were unaware of the hypothesis under study and participant allocation to each examiner was performed only on the basis of logistic procedures. Finally, although important evidence has emerged from our study regarding potential determinants of Type 1 postural pattern, the small number of participants showing this particular sagittal posture limits the statistical power of the comparisons conducted.

In our study, we were able to analyze the relation of individual and contextual characteristics with standing posture in a sample showing a wide range of values regarding diverse characteristics and also of sagittal standing spinopelvic organization. Our results support that specific groups among the adult population may be more likely to present morbidity relating to the spatial orientation of sagittal standing posture, such as those with older age, from a lower socioeconomic status, and presenting overall or central adiposity. In addition, higher BMI and central obesity were also strong plausible determinants of all nonneutral postural patterns.

Future strategies targeting excessive adiposity, preferably promoting physical activity, may favor overall sagittal balance. Concordantly, reducing the prevalence of overall and central obesity at a population level might prevent the occurrence of Type 1 postural pattern, whereas reducing overweight probably would decrease both Types 2 and 4 nonneutral postural patterns. Formal estimation of the effectiveness of overweight prevention and management in avoiding sagittal misalignment will be a valuable research object.

\section{References}

[1] Glassman SD, Bridwell K, Dimar JR, et al. The impact of positive sagittal balance in adult spinal deformity. Spine 2005;30:2024-9.

[2] Lafage V, Schwab F, Patel A, et al. Pelvic tilt and truncal inclination: two key radiographic parameters in the setting of adults with spinal deformity. Spine 2009;34:E599-606.

[3] Sánchez-Mariscal DF, Gómez-Rice A, Izquierdo NE, et al. Correlation of radiographic and functional measurements in patients who underwent primary scoliosis surgery in adult age. Spine 2012;37: 592-8.

[4] Schwab FJ, Smith VA, Biserni M, et al. Adult scoliosis: a quantitative radiographic and clinical analysis. Spine 2002;27:387-92.

[5] Murray CJ, Vos T, Lozano R, et al. Disability-adjusted life years (DALYs) for 291 diseases and injuries in 21 regions, 1990-2010: a systematic analysis for the Global Burden of Disease Study 2010. Lancet 2012;380:2197-223.

[6] Chaléat-Valayer E, Mac-Thiong JM, Paquet J, et al. Sagittal spinopelvic alignment in chronic low back pain. Eur Spine J 2011;20(5 Suppl):634-40.

[7] Jackson RP, McManus AC. Radiographic analysis of sagittal plane alignment and balance in standing volunteers and patients with low back pain matched for age, sex, and size. A prospective controlled clinical study. Spine 1994;19:1611-8.

[8] Korovessis P, Stamatakis M, Baikousis A. Segmental roentgenographic analysis of vertebral inclination on sagittal plane in asymptomatic versus chronic low back pain patients. J Spinal Disord 1999;12: $131-7$. 
[9] Roussouly P, Nnadi C. Sagittal plane deformity: an overview of interpretation and management. Eur Spine J 2010;19:1824-36.

[10] Ames CP, Smith JS, Scheer JK, et al. Impact of spinopelvic alignment on decision making in deformity surgery in adults: a review. J Neurosurg Spine 2012;16:547-64.

[11] Bonetti F, Curti S, Mattioli S, et al. Effectiveness of a "Global Postural Reeducation" program for persistent low back pain: a non-randomized controlled trial. BMC Musculoskelet Disord 2010;11:285.

[12] Diab AA, Moustafa IM. The efficacy of lumbar extension traction for sagittal alignment in mechanical low back pain: a randomized trial. J Back Musculoskelet Rehabil 2013;26:213-20.

[13] Vialle R, Levassor N, Rillardon L, et al. Radiographic analysis of the sagittal alignment and balance of the spine in asymptomatic subjects. J Bone Joint Surg Am 2005;87:260-7.

[14] Schwab F, Lafage V, Boyce R, et al. Gravity line analysis in adult volunteers: age-related correlation with spinal parameters, pelvic parameters, and foot position. Spine 2006;31:E959-67.

[15] Mac-Thiong JM, Roussouly P, Berthonnaud E, Guigui P. Age- and sex-related variations in sagittal sacropelvic morphology and balance in asymptomatic adults. Eur Spine J 2011;20(5 Suppl):572-7.

[16] Gelb DE, Lenke LG, Bridwell KH, et al. An analysis of sagittal spinal alignment in 100 asymptomatic middle and older aged volunteers. Spine 1995;20:1351-8.

[17] Janssen MM, Drevelle X, Humbert L, et al. Differences in male and female spino-pelvic alignment in asymptomatic young adults: a three-dimensional analysis using upright low-dose digital biplanar X-rays. Spine 2009;34:E826-32.

[18] Chanplakorn P, Sa-Ngasoongsong P, Wongsak S, et al. The correlation between the sagittal lumbopelvic alignments in standing position and the risk factors influencing low back pain. Orthop Rev (Pavia) 2012;4:e11.

[19] Boulay C, Tardieu C, Hecquet J, et al. Sagittal alignment of spine and pelvis regulated by pelvic incidence: standard values and prediction of lordosis. Eur Spine J 2006;15:415-22.

[20] Smith A, O'Sullivan P, Straker L. Classification of sagittal thoracolumbo-pelvic alignment of the adolescent spine in standing and its relationship to low back pain. Spine 2008;33:2101-7.

[21] Wang HJ, Giambini H, Zhang WJ, et al. A modified sagittal spine postural classification and its relationship to deformities and spinal mobility in a Chinese osteoporotic population. PLoS One 2012;7:e38560.

[22] Ramos E, Lopes C, Barros H. Investigating the effect of nonparticipation using a population-based case-control study on myocardial infarction. Ann Epidemiol 2004;14:437-41.

[23] Roussouly P, Gollogly S, Berthonnaud E, Dimnet J. Classification of the normal variation in the sagittal alignment of the human lumbar spine and pelvis in the standing position. Spine 2005;30:346-53.

[24] Duval-Beaupère G, Schmidt C, Cosson P. A Barycentremetric study of the sagittal shape of spine and pelvis: the conditions required for an economic standing position. Ann Biomed Eng 1992;20:451-62.

[25] Instituto do Emprego e Formação Profissional (IEFP). Classificação Nacional de Profissões, Versão 1994. IEFP; Lisboa, Portugal: 2001.

[26] Alves L, Azevedo A, Silva S, Barros H. Socioeconomic inequalities in the prevalence of nine established cardiovascular risk factors in a southern European population. PLoS One 2012;7:e37158.

[27] National Institutes of Health, National Heart Lung and Blood Institute. Clinical guidelines on the identification, evaluation, and treatment of overweight and obesity in adults: the evidence report. National Institutes of Health. Obes Res 1998;6(2 Suppl):51S-209S.

[28] Camões M, Severo M, Santos AC, et al. Testing an adaptation of the EPIC physical activity questionnaire in Portuguese adults: a validation study that assesses the seasonal bias of self-report. Ann Hum Biol 2010;37:185-97.
[29] Blair SN, Haskell WL, Ho P, et al. Assessment of habitual physical activity by a seven-day recall in a community survey and controlled experiments. Am J Epidemiol 1985;122:794-804.

[30] Subcommittee on the Tenth Edition of the Recommended Dietary A1lowances, Food and Nutrition Board, Commission on Life Sciences, National Research Council. Recommended dietary allowances. 10th ed. Washington, DC: National Research Council, National Academy Press, 1989.

[31] World Health Organization. Guidelines for controlling and monitoring the tobacco epidemic. Geneva, Switzerland: World Health Organization, 1998.

[32] Smith AJ, O'Sullivan PB, Beales DJ, et al. Trajectories of childhood body mass index are associated with adolescent sagittal standing posture. Int J Pediatr Obes 2011;6:e97-106.

[33] Houston DK, Stevens J, Cai J. Abdominal fat distribution and functional limitations and disability in a biracial cohort: the Atherosclerosis Risk in Communities Study. Int J Obes (Lond) 2005;29:1457-63.

[34] Backholer K, Wong E, Freak-Poli R, et al. Increasing body weight and risk of limitations in activities of daily living: a systematic review and meta-analysis. Obes Rev 2012;13:456-68.

[35] Kuh D, Bassey EJ, Butterworth S, et al. Grip strength, postural control, and functional leg power in a representative cohort of British men and women: associations with physical activity, health status, and socioeconomic conditions. J Gerontol A Biol Sci Med Sci 2005;60:224-31.

[36] Rantanen T, Era P, Heikkinen E. Physical activity and the changes in maximal isometric strength in men and women from the age of 75 to 80 years. J Am Geriatr Soc 1997;45:1439-45.

[37] Langsetmo L, Hitchcock CL, Kingwell EJ, et al. Physical activity, body mass index and bone mineral density-associations in a prospective population-based cohort of women and men: the Canadian Multicentre Osteoporosis Study (CaMos). Bone 2012;50:401-8.

[38] Hongo M, Miyakoshi N, Shimada Y, Sinaki M. Association of spinal curve deformity and back extensor strength in elderly women with osteoporosis in Japan and the United States. Osteoporos Int 2012;23:1029-34.

[39] Sinaki M, Itoi E, Rogers JW, et al. Correlation of back extensor strength with thoracic kyphosis and lumbar lordosis in estrogendeficient women. Am J Phys Med Rehabil 1996;75:370-4.

[40] Lafage V, Schwab F, Skalli W, et al. Standing balance and sagittal plane spinal deformity: analysis of spinopelvic and gravity line parameters. Spine 2008;33:1572-8.

[41] Strand BH, Cooper R, Hardy R, et al. Lifelong socioeconomic position and physical performance in midlife: results from the British 1946 birth cohort. Eur J Epidemiol 2011;26:475-83.

[42] Rapuri PB, Gallagher JC, Smith LM. Smoking is a risk factor for decreased physical performance in elderly women. J Gerontol A Biol Sci Med Sci 2007;62:93-100.

[43] Strand BH, Mishra G, Kuh D, et al. Smoking history and physical performance in midlife: results from the British 1946 birth cohort. J Gerontol A Biol Sci Med Sci 2011;66:142-9.

[44] Wüst RC, Morse CI, de Haan A, et al. Skeletal muscle properties and fatigue resistance in relation to smoking history. Eur J Appl Physiol 2008;104:103-10.

[45] Wong PK, Christie JJ, Wark JD. The effects of smoking on bone health. Clin Sci 2007;113:233-41.

[46] Ensrud KE, Black DM, Harris F, et al. Correlates of kyphosis in older women. The Fracture Intervention Trial Research Group. J Am Geriatr Soc 1997;45:682-7.

[47] Schneider DL, von Mühlen D, Barrett-Connor E, Sartoris DJ. Kyphosis does not equal vertebral fractures: the Rancho Bernardo study. J Rheumatol 2004;31:747-52. 